\title{
HEMOGLOBINÚRIA PAROXÍSTICA NOTURNA: DA FISIOPATOLOGIA AO TRATAMENTO
}

\author{
Martha Mariana de Almeida Santos Arruda ${ }^{1}$, Celso Arrais Rodrigues ${ }^{2}$, Mihoko Yamamoto ${ }^{3}$, Maria Stella Figueiredo ${ }^{4 *}$ \\ Trabalho realizado na Disciplina de Hematologia e Hemoterapia da Universidade Federal de São Paulo - UNIFESP, São Paulo, SP
}

*Correspondência:

Rua Botucatu, $740,3^{\circ}$ andar - Vila Clementino São Paulo - SP CEP: 04023-900

Telefone: (11) 5579-1550

- Fax: (11) 5571-8806

stella.figueiredo@unifesp.br

\section{RESUMO}

Hemoglobinúria paroxística noturna (HPN) é uma anemia hemolítica crônica adquirida rara, de curso clínico extremamente variável. Apresenta-se frequentemente com infecções recorrentes, neutropenia e trombocitopenia, e surge em associação com outras doenças hematológicas, especialmente com síndromes de falência medular, como anemia aplásica e síndrome mielodisplásica. É considerada ainda um tipo de trombofilia adquirida, apresentando-se com tromboses venosas variadas, com especial predileção por trombose de veias hepáticas e intra-abdominais, sua maior causa de mortalidade. A tríade anemia hemolítica, pancitopenia e trombose faz da HPN uma síndrome clínica única, que deixou de ser encarada como simples anemia hemolítica adquirida para ser considerada um defeito mutacional clonal da célula-tronco hematopoética (CTH). A mutação ocorre no gene da fosfaditilinositolglicana classe-A, e resulta no bloqueio precoce da síntese de âncoras de glicosilfosfaditilinositol $(\mathrm{GPI})$, responsáveis por manter aderidas à membrana plasmática dezenas de proteínas com funções específicas. A falência em sintetizar GPI madura gera redução de todas as proteínas de superfície normalmente ancoradas por ela. Dentre elas estão o CD55 e o CD59, que controlam a ativação da cascata do complemento. Assim, na HPN há aumento da susceptibilidade de eritrócitos ao complemento, gerando hemólise. Revisa-se aqui sua fisiopatologia, curso clínico, os tratamentos disponíveis com ênfase para o transplante de células-tronco hematopoéticas alogênicas e para o eculizumab, um anticorpo monoclonal humanizado que bloqueia a ativação do complemento terminal no nível C5 e previne a formação do complexo de ataque à membrana, a primeira droga a demonstrar eficácia no tratamento da HPN.

UnItermos: Resultado de tratamento. Hemoglobinúria paroxística. Revisão. Sintomas clínicos.

\section{INTRODUÇÃO}

Hemoglobinúria paroxística noturna (HPN) é uma anemia hemolítica crônica adquirida rara, de curso clínico extremamente variável. Apresenta-se freqüentemente com infecções recorrentes, neutropenia e trombocitopenia, e surge em associação com outras doenças hematológicas, especialmente com síndromes de insuficiência medular, como anemia aplásica e síndromes mielodisplásicas ${ }^{1}$. É considerada ainda um tipo de trombofilia adquirida, apresentandose com tromboses venosas variadas, com especial predileção por trombose de veias hepáticas e intra-abdominais, sua principal causa de mortalidade ${ }^{2}{ }^{3}$. Pela grande variedade de sintomas observados ao longo de seu curso, já foi chamada de "o grande imitador". A tríade anemia hemolítica, pancitopenia e trombose faz da HPN uma síndrome clínica única, que deixou de ser encarada como uma simples anemia hemolítica adquirida para ser considerada um defeito mutacional clonal da célula-tronco hematopoética4 ${ }^{4}$.
Casos compatíveis com HPN já haviam sido relatados em 1793, porém a descrição da doença como síndrome clínica foi feita apenas em 1882 por Paul Strubing ${ }^{5}$. 0 epônimo síndrome de MarchiafavaMicheli caiu em desuso pelo relato tardio e pequena contribuição destes autores para o entendimento da doença ${ }^{6}$. 0 termo hemoglobinúria paroxística noturna refere-se à descrição de destruição de eritrócitos com liberação de hemoglobina na urina, notada principalmente por coloração marrom-escura na primeira urina da manhã̃. 0 termo "noturna" se refere à crença inicial de que a hemólise seria desencadeada por acidose durante o sono; esta ativaria o complemento, que destruiria eritrócitos com membrana celular desprotegida ${ }^{8}$. Sabe-se hoje que a hemólise acontece durante todo o dia, mas a observação de hemoglobinúria ocorre pela manhã por causa do aumento da concentração urinária durante a noite.

Sua incidência não é totalmente conhecida, não só pela sua raridade como pela dificuldade diagnóstica que ela impõe. Nos

1. Residência médica em Hematologia e Hemoterapia pela Escola Paulista de Medicina - Universidade Federal de São Paulo - EPM/UNIFESP, e aluna do Programa de Pós-Graduação, Doutorado em Medicina - Hematologia da Universidade Federal de São Paulo EPM/UNIFESP, São Paulo, SP

2. Pós-doutorado em Hematologia pela Université de Paris e Pesquisador da Disciplina de Hematologia e Hemoterapia da Universidade Federal de São Paulo - UNIFESP, São Paulo, SP

3. Professora associada da Disciplina de Hematologia e Hemoterapia da Universidade Federal de São Paulo - UNIFESP, São Paulo, SP

4. Professora Associada Livre-Docente da Disciplina de Hematologia e Hemoterapia da Universidade Federal de São Paulo - UNIFESP, São Paulo, SP 
Estados Unidos estima-se um a cinco casos a cada milhão de habitantes, incidência cinco a 10 vezes menor que a de anemia aplásica. É provavelmente mais frequente no sul da Ásia e dentre os orientais. Pode ocorrer em qualquer idade, mas a maioria dos pacientes abre o diagnóstico entre a quarta e a quinta década de vida ${ }^{9}$. Crianças e adolescentes perfazem $10 \%$ dos casos e se apresentam mais frequentemente com bicitopenia ou pancitopenia, enquanto a trombose ocorre com igual frequência em todos os grupos etários ${ }^{1,4}$. Afeta homens e mulheres na mesma proporção, e não foi observada predisposição familiar ${ }^{9}$.

Sua história natural parece ser diferente entre americanos e europeus quando comparados com asiáticos. No geral, as manifestações de falência medular são mais comuns em asiáticos, enquanto trombose e infecção são mais frequentes em europeus e americanos. As bases destas diferenças fenotípicas não são conhecidas, mas é importante levá-las em consideração quando se tenta estabelecer um plano terapêutico ${ }^{1}$.

\section{Fisiopatologia}

HPN é causada pela expansão clonal não-maligna de uma ou mais células-tronco hematopoéticas que adquiriram mutação(ões) somática(s) no gene da fosfaditilinositolglicana classe-A (phosphatidyl inositol glycan-class $A, P(G-A)$, localizado no cromossomo $X^{10-12}$. Estas mutações resultam no bloqueio precoce da síntese de âncoras de glicosil-fosfaditilinositol (GPI), responsáveis por manter aderidas à membrana plasmática dezenas de proteínas com funções específicas ${ }^{2}$. A falência em sintetizar uma molécula madura de GPI gera ausência de todas as proteínas de superfície normalmente ancoradas por ela (Figura 1$)^{13}$. Consequentemente, as células sanguíneas advindas do clone HPN têm algum grau de deficiência destas proteínas, que pode ser parcial (células PNH tipo II, com cerca de $10 \%$ da expressão normal) ou total (células
HPN tipo III, com ausência completa da proteína $)^{10}$.

Dentre as proteínas ancoradas pela GPI estão os $\mathrm{CD}_{5} 5^{14} \mathrm{e}$ CD59 ${ }^{15}$, que têm o importante papel de controlar a ativação da cascata do complemento. Assim, a hemólise da HPN resulta do aumento da susceptibilidade de eritrócitos clonais ao complemento, pela redução ou ausência completa das proteínas regulatórias na superfície celular ${ }^{16}$. O sistema complemento consiste

Figura 1 - Esquema da estrutura da âncora glicosil-fosfaditilinositol

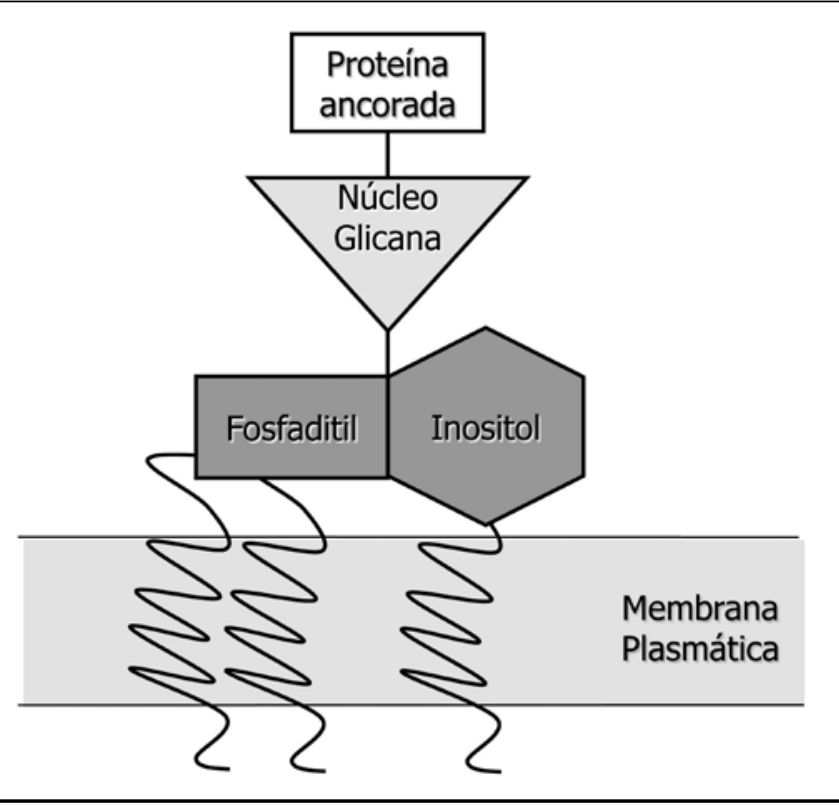

GPI é molécula responsável por manter aderidas à membrana plasmática dezenas de proteínas com funções específicas.

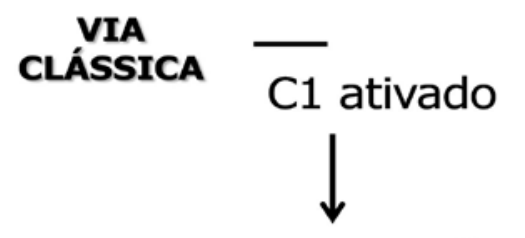

\section{Alvo da terapêutica com anticorpos anti-C5b}

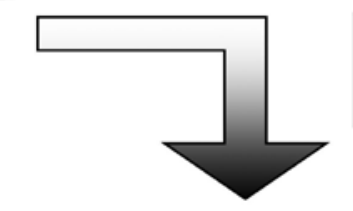

Prolectina
(MIRL, CD 59)

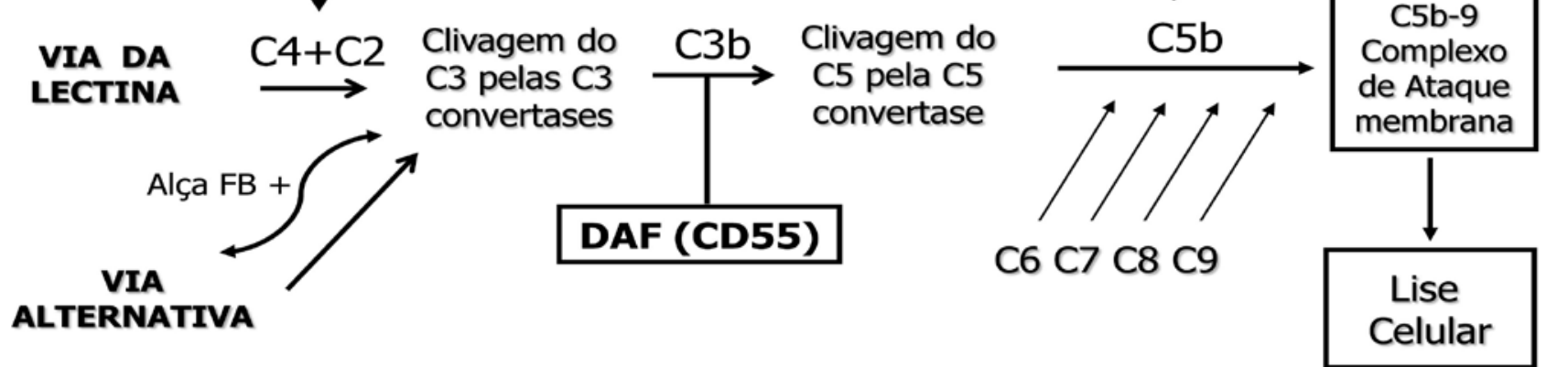

A partir de um estímulo externo (estresse metabólico, infecção, etc.), o C3b é formado pelas C3 convertases, através de uma das três vias de ativação (via clássica, via da lecitina e via alternativa). C3b, juntamente com as C5 convertases quebra C5, formando C5b, a reação pivô da cascata. C5b se une a C6-C9 para formação do complexo de ataque à membrana que, em última instância, causa lise celular. CD55 impede a formação do C3b e CD59 impede a formação do complexo de ataque à membrana, controlando a seqüência de reações. Como a formação do C5 é o passo limitante da cascata, anticorpos com a função de bloquear esta reação seriam um alvo terapêutico inteligente para HPN. 


\section{Figura 3 - Relação das proteínas reguladoras com o sistema}
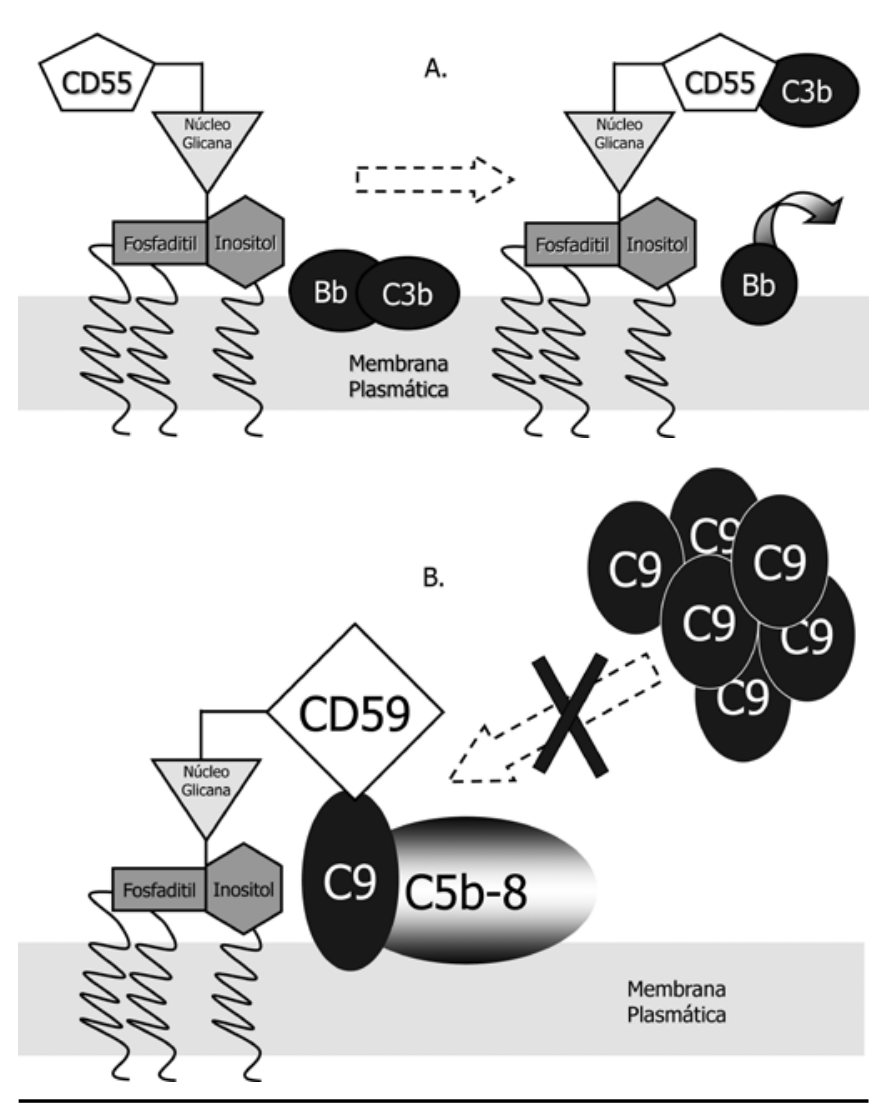

A: Interação do CD55 com o complexo C3bBb: Ao se ligar ao complexo C3b, CD55 gera dissociação do $\mathrm{Bb}$, prevenindo a lise da membrana do eritrócito. B: Interação do CD59 com o complexo C5b-C9: Ao se ligar ao C5b-C9, CD59 impede que outras moléculas de C9 se conjuguem ao complexo, inibindo a formação do complexo de ataque à membrana e, consequentemente, lise celular

em mais de 20 proteínas séricas que interagem em sequências precisas de ativação enzimática e ligação à membrana celular, gerando produtos com propriedades imunoprotetoras, imunorregulatórias, pró-inflamatórias e citolíticas. Pode ser ativado por três vias: via clássica, via da lecitina e via alternativa, sendo que as três resultam na geração de complexos C3-convertase, que mediam a quebra de $\mathrm{C} 3$ em C3a e C3b ${ }^{17}$ (Figura 2). Células HPN são vulneráveis à ativação do complemento por qualquer das três vias; como a via alternativa mantém um estado de ativação baixa, porém contínua, isto explica porque os pacientes com HPN têm hemólise crônica contínua.

O CD55 (ou decay accelerating factor) inibe o complemento no nível de C3, acelerando a taxa de destruição de C3-convertase ligada à membrana e reduzindo a quantidade de $\mathrm{C} 3$ dissociada a C3a e C3b (Figura 3). Já o CD59 (ou membrane inhibitor of reactive lysis) é uma glicoproteína que interage diretamente com o complexo de ataque à membrana (também chamado de complexo de complemento terminal - C5b-9) para impedir a formação do poro lítico na superfície celular a partir da agregação de C9 (Figura 4) ${ }^{13}$. A ausência de CD59 na superfície dos eritrócitos os torna susceptíveis à lise mediada pelo complexo de complemento terminal, o que explica a hemólise intravascular crônica com exacerbações, manifestação clínica primária da doença ${ }^{18}$. Das duas proteínas, CD59 é a mais importante na proteção contra lise celular mediada por complemento ${ }^{16}$.

O óxido nítrico (NO) é o maior regulador da fisiologia vascular, e muitas das manifestações clínicas da HPN são facilmente explicadas pela depleção tecidual de NO. Normalmente, a óxido nítrico sintetase do endotélio utiliza oxigênio e arginina para produzir NO. Este age na parede vascular para manter tônus e limitar ativação plaquetária. Hemoglobina livre tem enorme afinidade pelo NO e o retira de circulação ${ }^{19}$. Na HPN, a falência em regular o complemento na superfície eritrocítica leva à ampla hemólise intravascular, com liberação de grandes quantidades de hemoglobina livre e arginase eritrocitária no plasma, que depletam o NO e também a arginina, substrato para a sua síntese. A haptoglobina normalmente capta hemoglobina livre, mas suas altas concentrações em surtos hemolíticos acabam por exceder a capacidade de captação e clearance ${ }^{13}$.

Depleção tecidual de NO se manifesta clinicamente como astenia, dor abdominal, espasmo esofagiano, disfagia, impotência sexual masculina e possivelmente trombose. Todas estas manifestações clínicas são mais comuns no paciente com grandes populações de clone HPN ${ }^{1}$.

Em contraste com o conhecimento abundante em relação à hemólise, pouco se sabe sobre o mecanismo fisiopatológico da trombofilia ${ }^{1,11}$. Há evidência de que hemólise contribua para os episódios tromboembólicos, especialmente porque pacientes com clones HPN maiores também apresentam maior incidência de tromboembolismo, e estes eventos se correlacionam temporalmente com os surtos hemolíticos ${ }^{20}$. Apesar de o mecanismo não estar completamente esclarecido, hemólise foi implicada na inicialização de ativação e agregação plaquetárias. Estudos in vitro sugerem ainda que o complemento terminal possa ativar diretamente as plaquetas de pacientes com HPN². Além disto, ativação do complemento induz alteração das membranas de eritrócitos com formação de microvesículas, o que potencialmente contribui para a trombogênese ${ }^{21}$.

A ausência de proteínas normalmente ancoradas pela GPI também pode contribuir para o aumento de incidência de trombose. Citam-se o receptor do ativador de plasminogênio uroquinase, cuja ausência gera redução da fibrinólise local, e o inibidor da via do fator tecidual que, se ausente, permitiria o aumento da atividade pró-coagulante deste fator ${ }^{22}$.

Na HPN, a hematopoese ineficaz é secundária à redução da produção de células sanguíneas por hipoplasia medular ${ }^{23}$. Sabe-se que estes pacientes estão sob risco aumentado de desenvolverem anemia aplásica, e porcentagem significativa dos pacientes com diagnóstico estabelecido de anemia aplásica podem ser portadores de clones de HPN sem manifestações clínicas ${ }^{4}$. Anemia aplásica é considerada doença imunomediada, com destruição ativa das células-tronco hematopoéticas por linfócitos $T$ autorreativos ${ }^{24}$. Existe evidência experimental que células deficientes de proteínas ancoradas pela GPI sejam mais resistentes ao ataque de células NK e linfócitos $\mathrm{T}^{21}$, o que daria ao clone HPN uma vantagem adaptativa, num contexto de destruição imunomediada de células-tronco normais ${ }^{12}$. Especula-se ainda se as células com mutação da PIGA teriam papel no desenvolvimento da hipoplasia medular. A relação 
fisiopatológica definitiva entre estas duas doenças ainda não está bem determinada ${ }^{25}$, mas acredita-se que os processos envolvidos no desenvolvimento de ambas as doenças sejam semelhantes ${ }^{23}$.

\section{Diagnóstico}

Todos os pacientes com anemia hemolítica crônica adquirida e teste de Coombs negativo, especialmente aqueles com hemoglobinúria, devem ser investigados para HPN.

Pacientes com anemia aplásica e síndromes mielodisplásicas, especialmente as de baixo risco (anemia refratária, síndrome da deleção do $5 q$, citopenia refratária com displasia de múltiplas linhagens) devem ser avaliados, mesmo que não apresentem hemólise clinicamente manifesta. Recomenda-se identificar HPN subclínica porque há evidência de respostas melhores à terapêutica imunossupressora em pacientes com falência medular e clones HPN, mesmo que pequenos ${ }^{26}$.

Observa-se tromboembolismo como evento inicial na HPN em apenas 5\% dos casos; assim, não se recomenda a pesquisa em todos os pacientes com trombose. No entanto, pacientes com tromboses sem causa aparente, em sítios pouco usuais, ou associadas a citopenias e/ou hemólise devem ser avaliados sempre ${ }^{1}$.

Para o diagnóstico, inicialmente eram utilizados ensaios que avaliam hemólise de eritrócitos submetidos a condições que normalmente não geram hemólise. O teste da hemolisina ácida (teste de Ham) é um teste fácil e prontamente disponível que pesquisa hemólise em eritrócitos incubados com plasma levemente ácido $(\mathrm{pH} 6,2)^{8}$. A acidificação do plasma ativa o complemento, que hemolisa células sensíveis. Sua especificidade é de $100 \%$, porém tem baixa sensibilidade e não pode ser utilizado para medir tamanho de clone. 0 teste de lise por sacarose também é de fácil realização. A adição de sacarose a soro normal ativa o circuito clássico do complemento, com hemólise de eritrócitos sensíveis ${ }^{27}$. É pouco mais sensível que o teste de Ham, mas perde em especificidade. Apesar de sua boa especificidade ambos os testes têm baixa sensibilidade e podem estar falsamente negativos em pacientes com clones pequenos, que sofreram hemólise recente ou que receberam transfusão de sangue ${ }^{28}$. Atualmente sua importância é apenas histórica, não sendo mais recomendados na triagem de HPN ${ }^{1}$.

$\mathrm{O}$ teste da sensibilidade à lise por complemento utiliza um número conhecido de eritrócitos sensibilizados com anticorpo tratados com soro normal e quantidades conhecidas crescentes de complemento. A quantidade de complemento necessária para lisar 50\% dos eritrócitos é utilizada como índice para a quantificação da sensibilidade pelo complemento ${ }^{29}$. A descrição deste teste possibilitou a observação de duas populações em pacientes com HPN: uma com grande sensibilidade à lise por quantidades ínfimas de complemento, atualmente chamado de clone HPN III, e outra com sensibilidade pouco aumentada em relação a células normais (clone HPN II). Apesar de ser um teste muito preciso, é de grande dificuldade técnica, não estando disponível na maior parte dos laboratórios.

A citometria de fluxo é o exame de escolha na investigação de HPN, por ser capaz de avaliar a expressão de proteínas ancoradas pela GPI com alta sensibilidade e especificidade ${ }^{30}$. Esta tecnologia está amplamente disponível, laboratórios de hematologia e imunologia utilizam citometria de fluxo tanto em pesquisa como na clínica diária. Como trata-se de ferramenta fundamental para diagnóstico de leucemias agudas, todos os serviços que atendem pacientes com leucemias agudas têm capacidade de rastreio de HPN, embora seja necessária uma adequada padronização. Para diagnóstico, a fim de se evitar falsos resultados, se utilizam pelo menos dois anticorpos monoclonais, direcionadas contra duas proteínas ancoradas pela GPI diferentes, em pelo menos duas linhagens celulares ${ }^{13}$. Transfusões recentes não alteram 0 diagnóstico, tendo em vista que podem ser avaliados granulócitos e monócitos, células que não têm sua meia-vida alterada por transfusões ou pela presença da mutação ${ }^{31}$. A porcentagem de células com deficiência de proteínas $\mathrm{GPI}$-ancoradas é reflexo direto do tamanho do clone $\mathrm{HPN}^{32}$, e este dado tem importância clínica e prognóstica ${ }^{33}$.

\section{Curso clínico}

A hemólise crônica traz grande morbidade para os pacientes afetados $^{34}$. Eles se queixam de letargia, astenia, mialgia difusa e perda da sensação de bem-estar, o que significativamente reduz a qualidade de vida ${ }^{35}$. Durante os surtos de hemólise intravascular aguda, os chamados paroxismos, ocorre hemoglobinúria, notada por urina marrom-escura, que pode vir acompanhada de sintomas gastrointestinais, náuseas, icterícia, dor abdominal (inclusive simulando abdome agudo²), disfagia, espasmo esofagiano, disfunção erétil masculina e piora da astenia ${ }^{19}$. Os sintomas de HPN são geralmente desproporcionais ao grau de anemia $^{10}$. Existe ainda evidência de redução de função renal pelo depósito de hemossiderina no parênquima renal ${ }^{36}$ e, como já foi dito, parece haver correlação entre hemólise e episódios tromboembólicos.

A hemólise pode ser monitorada pelos níveis séricos da enzima desidrogenase láctica (DHL), liberada em situações de destruição de hemácias. Esta enzima está tipicamente aumentada em pacientes com HPN, podendo chegar a até 20 vezes o limite superior da normalidade durante paroxismos graves ${ }^{37}$.

A história natural da HPN foi definida a partir de várias series de casos analisadas retrospectivamente, em diferentes populações. Não há nenhuma publicação em relação à história natural da HPN em pacientes brasileiros. Os trabalhos publicados estudando pacientes brasileiros analisaram as mutações do gene PIG-A, buscando identificar o perfil de mutação no Brasil. 0 perfil encontrado foi semelhante nos dois trabalhos: predomínio de mutações de ponto com presença de mutações novas, não anteriormente relatadas ${ }^{38,39}$. Estes dados confirmaram estudos prévios em relação à grande variabilidade das mutações de PIG-A encontradas em HPN nas diferentes populações e também o fato de que elas não apresentam correlação com o curso clínico da doença ${ }^{40-42}$.

O maior grupo de estudo de história natural da HPN já publicado vem do Registro de Pacientes da Sociedade Francesa de Hematologia. Este é um estudo retrospectivo envolvendo 220 pacientes que receberam diagnóstico de HPN na França entre 1950 e 1995, e é considerado grande o suficiente para estabelecer curso clínico e prognóstico da doença9 ${ }^{9}$. Em 2008 ele foi expandido e atualizado, somando 460 pacientes, com mediana do tempo de acompanhamento de sete anos ${ }^{25}$.

Complicações trombóticas são clássicas, podendo ocorrer em mais da metade dos pacientes após 15 anos do diagnóstico, 
com incidências maiores em latinos e afro-americanos que em orientais ${ }^{43}$. Estima-se que cerca de $40 \%$ dos pacientes com HPN apresentarão algum evento trombótico ao longo da vida ${ }^{11}$, sendo que aqueles com clones maiores estão sob maior risco de desenvolver tromboembolismo 32,33,44. Embora haja evidência de incidência aumentada desta complicação em leitos arteriais ${ }^{11}$, ela é pronunciadamente mais frequente em territórios vasculares venosos, envolvendo principalmente veias hepáticas, cerebrais e sistemas venosos profundos dos membros ${ }^{1}$.

A associação entre HPN e anemia aplásica foi inicialmente levantada por Dacie ${ }^{45}$ e Lewis $^{46}$ e hoje é sabido que a maior parte dos pacientes com HPN tem alguma evidência de falência medular. Os estudos de história natural confirmaram esta associação, com detecção de clone HPN em pacientes com antecedente de anemia aplásica variando entre $23 \%{ }^{25}$ e $38 \%{ }^{32}$. Por outro lado, observou-se aparecimento de trombocitopenia, neutropenia em associação à anemia em mais de 65\% dos pacientes franceses com HPN. Em 15\% deles foi observada evolução para pancitopenia, com a incidência cumulativa estendida desta complicação em torno de $20 \%$ em oito anos ${ }^{9}$.

Síndromes mielodisplásicas e leucemia aguda também são complicações clássicas da HPN. A incidência de leucemia varia de $1 \%$ a $3 \%{ }^{9}$, mas já foi relatada incidência de até $7,5 \%$ (série de casos japoneses) ${ }^{47}$. Considerando-se os estudos de história natural, nos quais nem sempre foi possível a utilização de citometria de fluxo de alta sensibilidade, a incidência de síndrome mielodisplásica é próxima a $5 \%{ }^{9}$. No entanto, com o advento de citômetros com capacidade de detectar clones GPI-deficientes de até $0,003 \%$, tem-se observado a presença de clones HPN em até $20 \%$ dos pacientes com síndrome mielodisplásica de baixo risco ${ }^{48}$

Outras complicações observadas: hemocromatose nos pacientes politransfundidos que não espoliam ferro pela urina, infecções transmitidas por hemotransfusão e maior incidência de tumores sólidos em relação à população geral corrigida para idade e gênero ${ }^{9}$.

As maiores causas de morte dos pacientes com HPN são trombose, infecção e doenças malignas, podendo ainda ocorrer hemorragia fatal nos pacientes plaquetopênicos. As estimativas de sobrevida em 10 anos foram de 66\% na série de casos francesa $^{9}, 50 \%$ na série inglesa ${ }^{49}$ e $71 \%$ na série japonesa ${ }^{47}$.

Por meio de análises multivariadas, foram definidos sete fatores capazes de influenciar independentemente sobrevida em pacientes com HPN. São eles: complicações trombóticas, independentemente da localização (risco relativo - RR 10.2), desenvolvimento de pancitopenia (RR 5.5), desenvolvimento de síndrome mielodisplásica ou leucemia aguda (RR 19.1), idade maior que 55 anos, necessidade de tratamentos adicionais e trombocitopenia ao diagnóstico (RR 2.2) $)^{9}$.

Por outro lado, autores ingleses observaram até 15\% de remissão clínica espontânea, sem definição dos mecanismos prováveis ou dos fatores identificadores da evolução destes pacientes ${ }^{50}$.

\section{Tratamentos disponíveis}

Pacientes com HPN são com frequência ferropênicos, pela perda constante de ferro na urina (hemossiderinúria e hemoglobinúria). Assim, muitas vezes é necessária a reposição deste elemento, já que a deficiência de ferro limita a eritropoese ${ }^{51}$. Além disso, recomenda-se também a reposição de folatos, que são espoliados pela eritropoese aumentada secundária à hemólise crônica ${ }^{52}$.

A associação entre hemólise contínua e hematopoese ineficaz pode levar à dependência transfusional. Além de aumentar a concentração de hemoglobina, transfusões podem reduzir hemólise a partir da supressão da eritropoese normal e clonal. Apesar de toda a tecnologia envolvida nos processos de hemoterapia da atualidade, com a crescente preocupação em evitar as principais complicações transfusionais, incluídas aí infecções crônicas passíveis de transmissão pelo sangue, hemotransfusão ainda é um procedimento de risco. Assim, o ideal é restringir as transfusões ao mínimo necessário. Em pacientes com grande componente de hematopoese ineficaz, a sobrecarga de ferro passa a ser um problema relevante, inclusive com necessidade de uso crônico de quelantes ${ }^{1}$.

Anticoagulação pode ser indicada profilaticamente para pacientes com grandes clones e outros fatores de risco para complicações trombóticas ${ }^{33}$. Por outro lado, pacientes que já apresentaram um evento tromboembólico deverão ser anticoagulados por toda a vida, ou enquanto houver persistência do clone HPN ${ }^{1}$.

Em pacientes com anemia aplásica grave e sintomas mais relacionados a esta doença que à própria HPN, indica-se em primeira linha tratamento imunossupressor ou transplante de células-tronco hematopóeticas alogênicas (TCTHa). Os corticosteroides e os andrógenos, abordagens primariamente utilizadas no tratamento de anemia aplásica, não têm comprovação de eficácia clínica que contrabalance os riscos ${ }^{1}$, mas ainda são muito utilizados pela sua disponibilidade.

Até recentemente não se conhecia tratamento eficaz de baixo risco que bloqueasse a hemólise crônica e/ou reduzisse sintomas em pacientes com HPN. Os tratamentos disponíveis eram primariamente de suporte e as demais opções eram limitadas, com índice-terapêutico desfavorável e resultados insatisfatórios, além de resposta ruim ou com alto perfil de toxicidade ${ }^{34}$.

\section{Transplante de Células-Tronco Hematopoéticas}

O único tratamento curativo para HPN é o TCTHa, porém este está associado a morbimortalidade considerável ${ }^{28}$. Em um grupo de pacientes submetidos a TCTHa aparentado entre 1975 e 1995, com mediana de idade de 28 anos, observou-se $56 \%$ de sobrevida em dois anos ${ }^{53}$. Não há complicações especificamente relacionadas à HPN; observou-se falha de pega do enxerto em cerca de $6 \%$ e doença do enxerto-versus-hospedeiro aguda e crônica em $15 \%$ a $30 \%$ e $20 \%$ a $35 \%$ dos pacientes transplantados, respectivamente 23,54 . Por outro lado, a possibilidade de utilização de células-tronco de cordão umbilical, da avaliação de compatibilidade de doadores não-aparentados no nível molecular, além da disponibilidade de condicionamentos menos tóxicos e a melhoria do suporte clínico pós-transplante vem aumentando suas taxas de sucesso ${ }^{23}$.

Há relatos bem sucedidos de transplantes mieloablativos ${ }^{55}$ e não-mieloablativos ${ }^{56}$, tanto de doadores aparentados quanto de doadores de banco de doadores ${ }^{57}$. As taxas de cura parecem ser maiores nos transplantes alogênicos que nos singênicos, o que indica que o efeito "enxerto-versus-clone HPN" deva ser importante para o sucesso desta modalidade terapêutica ${ }^{58}$. 
Atualmente indica-se transplante apenas para os pacientes com fatores de risco para pior evolução de doença e morte ${ }^{1}$, especialmente nos casos de síndromes de falência medular com citopenias graves. Ainda, alguns autores consideram o TCTHa o primeiro tratamento para crianças e adolescentes com HPN e anemia aplásica, considerando-se que pacientes mais jovens, apesar de apresentarem boa resposta ao tratamento imunossupressor, apresentam sobrevida curta por recaída ${ }^{23}$.

Infelizmente, ainda hoje a maioria dos pacientes não é candidata ao TCTHa, ou por não terem condições clínicas de serem submetidos ao procedimento, ou pela ausência de doadores ${ }^{13}$. Além disso, pelo fato de a doença não ter um curso definido de progressão, inclusive com possibilidade de remissão espontânea $^{9,50}$, e com a recente evidência de eficácia do eculizumab em relação à hemólise e na prevenção de tromboembolismo, há dúvidas em relação ao melhor momento para realizá-lo .

\section{Eculizumab}

Em 2002 foram publicados os primeiros trabalhos descrevendo o eculizumab (Soliris ${ }^{\circledR}$; Alexion Pharmaceuticals, Cheshire, CT $)^{59,60}$. Trata-se de um anticorpo monoclonal humanizado que bloqueia a ativação do complemento terminal no nível C5 e previne a formação de C5a e o complexo de ataque à membrana C5-961. Foi a primeira droga a demonstrar eficácia no tratamento de HPN e por isto foi aprovada pela Comissão Europeia e pelo Departamento de Alimentos e Drogas americano em $2007^{13}$.

O eculizumab já foi avaliado em dois estudos fase III, o estudo TRIUMPH ${ }^{10}$, multicêntrico, internacional, duplo-cego, randomizado e o ensaio SHEPHERD ${ }^{34}$, open label, não-controlado. TRIUMPH demonstrou que o eculizumab é capaz de estabilizar os níveis de hemoglobina e reduzir as necessidades transfusionais em pacientes com HPN clássica. Foram incluídos 87 pacientes, com necessidade transfusional mínima de quatro unidades de concentrados de hemácias no ano anterior ao do estudo, com DHL de pelo menos 1,5 vezes o limite normal superior e contagem plaquetária maior que $100 \times 10^{9}$ células/L. Eles foram randomizados para receber placebo $(n=44)$ ou eculizumab ( $n=43$ ) na dose de $600 \mathrm{mg} / \mathrm{semana}$ por quatro semanas, 900 mg/semana por uma semana e 900 mg a cada duas semanas por seis meses. A estabilização da hemoglobina ocorreu em $48,8 \%$ dos pacientes no grupo eculizumab e $0 \%$ no grupo placebo ( $p<0,001$ ). A mediana de unidades de concentrados de hemácias foi de zero no grupo eculizumab e 10 no grupo placebo ( $p=0,001$ ). 0 grupo eculizumab também apresentou melhora significativa em índices que medem qualidade de vida e redução dos níveis de DHL. Os efeitos adversos mais comuns observados no grupo eculizumab foram cefaleia, nasofaringite, dor lombar e infecções do trato respiratório superior.

O estudo SHEPHERD foi desenhado para avaliação de segurança e eficácia da droga numa população de pacientes com HPN maior e mais heterogênea ${ }^{34}$. Noventa e sete pacientes de mais de 30 centros internacionais foram selecionados, dentre eles alguns com necessidades transfusionais mínimas e plaquetopenia até $30 \times 10^{9}$ plaquetas/L. Eculizumab foi administrado por 52 semanas utilizando-se as doses descritas acima. Efeitos adversos foram semelhantes aos observados no TRIUMPH e observou-se redução significativa da hemólise, com aumento dos níveis de hemoglobina, redução da dependência transfusional, menos fadiga e aumento da qualidade de vida. Esses dados confirmaram a eficácia e a segurança observada no estudo TRIUMPH, em pacientes menos selecionados.

O bloqueio do complemento no nível de C5 teoricamente preserva a atividade dos componentes prévios da cascata, necessários para a opsonização de micro-organismos e clearance de complexos imunes. No entanto, como o bloqueio do complemento terminal pode estar associado com aumento de infecções por Neisseria meningitidis, todos os pacientes tratados até os dias atuais com eculizumab foram previamente vacinados contra $N$. meningitidis. Não se observou aumento de incidência de infecções nos pacientes tratados com eculizumab quando comparados com os tratados com placebo, inclusive considerando-se infecções sérias ou múltiplas.

Dos 195 pacientes envolvidos nestes dois ensaios fase III e em um ensaio fase $\|^{37}, 187$ completaram o tempo de observação e foram incluídos num outro estudo open label fase III para receber eculizumab por dois anos, desenhado para avaliar a incidência de trombose nos pacientes antes e durante 0 tratamento com eculizumab ${ }^{20}$. A taxa de tromboembolismo nos tratados foi de 1,07 eventos/100 pacientes-ano, comparados com 7,37 eventos/100 pacientes-ano $(p<0,001)$ antes do tratamento. Isso se traduz numa redução de risco absoluto de trombose de $85 \%{ }^{20}$. Idealmente deveria ser conduzido um estudo randomizado placebo-controlado para determinar se eculizumab é capaz de prevenir trombose. Porém, dada a raridade da doença, provavelmente este estudo nunca será realizado ${ }^{13}$. Por outro lado, a evidência disponível mostra redução importante do risco de trombose nos pacientes utilizando a droga, o que ajuda a justificar seu uso e leva alguns autores a encarar tromboembolismo como indicação absoluta para se iniciar tratamento com eculizumab ${ }^{28}$. Por outro lado, ainda não está definido para quais pacientes deve-se oferecer anticoagulação profilática ${ }^{33}$ e se é seguro suspender anticoagulação de pacientes com antecedente de trombose utilizando eculizumab.

No Brasil o eculizumab está em processo de regulamentação pela Agência Nacional de Vigilância Sanitária e deve estar disponível no mercado ainda em 2010. A grande desvantagem da droga é seu custo, que gira em torno de 400.000 dólares por ano por paciente nos Estados Unidos ${ }^{23}$, e a necessidade de tratamento contínuo para manutenção do efeito. Além disso, a droga a princípio não tem efeito sobre a alteração mutacional da célula-tronco hematopoética e sobre a falência medular. Assim, pacientes com HPN associada a anemia aplásica ou síndromes mielodisplásicas como manifestações primárias terão sua melhor chance terapêutica em esquemas de imunossupressão e no TCTHa ${ }^{25}$.

\section{Conclusão}

Pacientes com anemia hemolítica adquirida Coombs-negativa, tromboses inexplicadas especialmente em sítios pouco comuns, citopenias e síndromes de falência medular, disfagia, odinofagia, dores abdominais e impotência sexual masculina sem causa aparente devem ser submetidos à pesquisa para HPN. Tendo em vista os avanços recentes no entendimento da doença, sua alta morbimortalidade e a disponibilidade de tratamentos eficazes, inclusive com potencial de cura, é fundamental que 
os médicos pensem neste diagnóstico. Os portadores de HPN podem se beneficiar amplamente dos tratamentos disponíveis, com redução do risco de sequelas graves e melhora considerável da qualidade de vida.

\section{SUPORTE FinANCEIRO:}

FAPESP, projeto 04/12342-4

\section{Conflito de interesse: não há}

\section{SUMmarY}

\section{Paroxysmal nocturnal hemoglobinURIA: FROM PHYSIOPATHOLOGY TO TREATMENT}

Paroxysmal nocturnal hemoglobinuria $(P N H)$ is a rare disorder, an acquired chronic hemolytic anemia, often associated with recurrent nocturnal exacerbations, recurrent infections, neutropenia, thrombocytopenia, and episodes of venous thrombosis. Its clinical course is highly variable. It frequently arises in association with bone marrow failure, particularly aplastic anemia and myelodysplastic syndrome. It is also an acquired thrombophilia, presenting with a variety of venous thrombosis, mainly manifested with intra-abdominal thrombosis, here the major cause of mortality. The triad of hemolytic anemia, pancytopenia, and thrombosis makes a truly unique clinical syndrome of $\mathrm{PNH}$, which was reclassified from a purely acquired hemolytic anemia to a hematopoietic stem cell mutation defect of the phosphatidyl inositol glycanclass-A gene. This mutation results in an early block in the synthesis of glycosylphosphatidylinositol (GPI) anchors, responsible for binding membrane functional proteins. Among these proteins are the complement inhibitors, especially CD55 and CD59, that play a key role in protecting blood cells from complement cascade attack. Therefore, in PNH occurs an increased susceptibility of red cells to complement, and consequently, hemolysis. We here review PNH physiopathology, clinical course, and treatment options, especially eculizumab, a humanized monoclonal antibody that blocks the activation of terminal complement at C5 and prevents formation of the terminal complement complex, the first effective drug therapy for PNH. [Rev Assoc Med Bras 2010; 56(2): 214-21]

KEY WORDS: Paroxysmal nocturnal hemoglobinuria. Treatment outcome. Clinical symptoms. Review.

\section{REFERÊNCIAS}

1. Parker C, Omine M, Richards S, Nishimura J, Bessler M, Ware R, et al. Diagnosis and management of paroxysmal nocturnal hemoglobinuria. Blood. 2005;106(12):3699-709

2. Mathieu D, Rahmouni A, Villeneuve P, Anglade MC, Rochant H, Vasile N. Impact of magnetic resonance imaging on the diagnosis of abdominal complications of paroxysmal nocturnal hemoglobinuria. Blood. 1995;85(11):3283-8.

3. Ware RE, Hall SE, Rosse WF. Paroxysmal nocturnal hemoglobinuria with onset in childhood and adolescence. N Engl J Med. 1991;325(14):991-6.

4. Besa EC. Paroxysmal nocturnal hemoglobinuria, in eMedicine. 2007, WebMD.

5. Crosby WH. Paroxysmal nocturnal hemoglobinuria; a classic description by Paul Strubling in 1882, and a bibliography of the disease. Blood. 1951;6(3)270-84.

6. Parker CJ. Paroxysmal nocturnal hemoglobinuria: an historical overview. Hematology Am Soc Hematol Educ Program. 2008;2008:93-103.

7. Crosby WH. Paroxysmal nocturnal hemoglobinuria: relation of the clinical manifestations to underlying pathogenic mechanisms. Blood. 1953;8(9)769-812.
8. Ham TH, Dingle JH. Studies on destruction of red blood cells. Ii. chronic hemolytic anemia with paroxysmal nocturnal hemoglobinuria: certain immunological aspects of the hemolytic mechanism with special reference to serum complement. J Clin Invest. 1939;18(6)657-72.

9. Socie G, et al. Paroxysmal nocturnal haemoglobinuria: long-term followup and prognostic factors. French Society of Haematology. Lancet. 1996;348(9027)573-7.

10. Hillmen P, Young NS, Schubert J, Brodsky RA, Socié G, Muus P, et al. The complement inhibitor eculizumab in paroxysmal nocturnal hemoglobinuria. N Engl J Med. 2006;355(12):1233-43.

11. Bessler M, Hiken J. The pathophysiology of disease in patients with paroxysmal nocturnal hemoglobinuria. Hematology Am Soc Hematol Educ Program. 2008;2008:104-10

12. Brodsky RA. Paroxysmal nocturnal hemoglobinuria: stem cells and clonality. Hematology Am Soc Hematol Educ Program. 2008;2008:111-5.

13. Brodsky RA. Advances in the diagnosis and therapy of paroxysmal nocturnal hemoglobinuria. Blood Rev. 2008;22(2):65-74.

14. Sugarman J, Devine DV, Rosse WF, Structural and functional differences between decay-accelerating factor and red cell acetylcholinesterase. Blood. $1986 ; 68(3): 680-4$

15. Shichishima T, Terasawa T, Hashimoto C, Ohto H, Uchida T, Maruyama Y. Heterogenous expression of decay accelerating factor and CD59/membrane attack complex inhibition factor on paroxysmal nocturnal haemoglobinuria (PNH) erythrocytes. Br J Haematol. 1991;78(4):545-50.

16. Smith LJ. Paroxysmal nocturnalhemoglobinuria.Clin LabSci. 2004;17(3):172-7.

17. Walport MJ. Complement. First of two parts. N Engl J Med. 2001;344(14):1058-66.

18. Dacie J. Paroxysmal nocturnal haemoglobinuria $>\operatorname{In}$ : The haemolytic anaemias: congenital and acquired. London: J \& A Churchill Ltd; 1967. p.1128-260.

19. Rother RP, Bell L, Hillmen P, Gladwin MT. The clinical sequelae of intravascular hemolysis and extracellular plasma hemoglobin: a novel mechanism of human disease. JAMA. 2005:293(13):1653-62.

20. Hillmen P, Muus P, Dührsen U, Risitano AM, Schubert J, Luzzatto L, et al. Effect of the complement inhibitor eculizumab on thromboembolism in patients with paroxysmal nocturnal hemoglobinuria. Blood. 2007;110(12):4123-8.

21. Meletis J, Terpos E. Recent insights into the pathophysiology of paroxysmal nocturnal hemoglobinuria. Med Sci Monit. 2003;9(7):RA161-72.

22. Rosse WF. Pathogenesis of paroxysmal nocturnal hemoglobinuria: missing cell proteins. UpToDate 16.2 [CD] 2008 02/15/2008. [cited 2008 aug 18]. Available from: http://www.uptodate.com/home/index.html.

23. Parker CJ. Bone marrow failure syndromes: paroxysmal nocturnal hemoglobinuria. Hematol Oncol Clin North Am. 2009;23(2):333-46.

24. Young NS, Scheinberg P, Calado RT. Aplastic anemia. Curr Opin Hematol. 2008;15(3): 162-8

25. De Latour, RP, Mary JY, Salanoubat C, Terriou L, Etienne G, Mohty M, et al. Paroxysmal nocturnal hemoglobinuria: natural history of disease subcategories. Blood. 2008;112(8):3099-106.

26. Wang $\mathrm{H}$, Chuhjo T, Yasue $\mathrm{S}$, Omine M, Nakao S. Clinical significance of a minor population of paroxysmal nocturnal hemoglobinuria-type cells in bone marrow failure syndrome. Blood. 2002;100(12):3897-902.

27. Hartmann RC, Jenkins DE. The "sugar-water" test for paroxysmal nocturnal hemoglobinuria. N Engl J Med. 1966;275(3):155-7.

28. Brodsky RA. How I treat paroxysmal nocturnal hemoglobinuria. Blood. 2009;113(26):6522-7.

29. Rosse, WF, Dacie JD. Immune lysis of normal human and paroxysmal nocturnal hemoglobinuria $(\mathrm{PNH})$ red blood cells. I. The sensitivity of PNH red cells to lysis by complement and specific antibody. J Clin Invest. 1966;45(5):736-48.

30. Hall SE, Rosse WF. The use of monoclonal antibodies and flow cytometry in the diagnosis of paroxysmal nocturnal hemoglobinuria. Blood. 1996;87(12):5332-40

31. Brubaker LH, Essig LJ, Mengel CE. Neutrophil life span in paroxysmal nocturnal hemoglobinuria. Blood. 1977;50(4):657-62.

32. Nishimura J, Kanakura Y, Ware RE, Shichishima T, Nakakuma H, Ninomiya $\mathrm{H}$, et al. Clinical course and flow cytometric analysis of paroxysmal nocturnal hemoglobinuria in the United States and Japan. Medicine (Baltimore). 2004;83(3): 193-207.

33. Hall C, Richards S, Hillmen P. Primary prophylaxis with warfarin prevents thrombosis in paroxysmal nocturnal hemoglobinuria $(\mathrm{PNH})$. Blood. 2003;102(10):3587-91.

34. Brodsky RA, Young NS, Antonioli E, Risitano AM, Schrezenmeier H, Schubert $J$, et al. Multicenter phase 3 study of the complement inhibitor eculizumab for the treatment of patients with paroxysmal nocturnal hemoglobinuria. Blood. 2008;111(4):1840-7.

35. Rosse W. Paroxysmal nocturnal hemoglobinuria. In: Hoffman R, Shattil SJ, editors. Hematology: basic principals and practice. New York: Churchill Livingstone: New York; 2000. p.331-42.

36. Kumpers P, Herrmann A, Lotz J, Mengel M, Schwarz A. A blue kidney--chronic renal failure as a consequence of siderosis in paroxysmal nocturnal hemoglobinuria? Clin Nephrol. 2006;66(3):210-3. 
37. Hill A, Hillmen P, Richards SJ, Elebute D, Marsh JC, Chan J, et al. Sustained response and long-term safety of eculizumab in paroxysmal nocturnal hemoglobinuria. Blood. 2005;106(7):2559-65.

38. Franco De Carvalho R, Arruda VR, Saad ST, Costa FF. Detection of somatic mutations of the PIG-A gene in Brazilian patients with paroxysmal nocturnal hemoglobinuria. Braz J Med Biol Res. 2001;34(6):763-6.

39. Bidoia BG. Estudo molecular do gene PIG-A na hemoglobinúria paroxística noturna [tese]. São Paulo: Escola Paulista, Universidade Federal de São Paulo; 1999.

40. Kinoshita T, Inoue N, Takeda J. Role of phosphatidylinositol-linked proteins in paroxysmal nocturnal hemoglobinuria pathogenesis. Annu Rev Med. 1996;47:1-10.

41. Pramoonjago $P$, Wanachiwanawin W, Chinprasertsak S, Pattanapanayasat K, Takeda J, Kinoshita T. Somatic mutations of PIG-A in Thai patients with paroxysmal nocturnal hemoglobinuria. Blood. 1995;86(5):1736-9.

42. Yamada N, Miyata T, Maeda K, Kitani T, Takeda J, Kinoshita T. Somatic mutations of the PIG-A gene found in Japanese patients with paroxysmal nocturnal hemoglobinuria. Blood. 1995; 85(4):885-92.

43. Araten DJ, Thaler HT, Luzzatto L. High incidence of thrombosis in AfricanAmerican and Latin-American patients with paroxysmal nocturnal haemoglobinuria. Thromb Haemost. 2005;93(1):88-91.

44. Moyo VM, Mukhina GL, Garrett ES, Brodsky RA. Natural history of paroxysmal nocturnal haemoglobinuria using modern diagnostic assays. Br J Haematol. 2004;126(1):133-8.

45. Dacie JV, Lewis SM. Paroxysmal nocturnal haemoglobinuria: variation in clinical severity and association with bone-marrow hypoplasia. Br J Haematol. $1961 ; 7: 442-57$.

46. Lewis SM, Dacie JV. The aplastic anaemia--paroxysmal nocturnal haemoglobinuria syndrome. Br J Haematol. 1967;13(2):236-51.

47. Fujioka S, Asai T, Prognostic features of paroxysmal nocturnal hemoglobinuria in Japan. Nippon Ketsueki Gakkai Zasshi. 1989;52(8):1386-94.

48. Wang SA, Pozdnyakova O, Jorgensen JL, Medeiros LJ, Stachurski D, Anderson $\mathrm{M}$, et al. Detection of paroxysmal nocturnal hemoglobinuria clones in patients with myelodysplastic syndromes and related bone marrow diseases, with emphasis on diagnostic pitfalls and caveats. Haematologica. 2009;94(1):29-37.

49. Hillmen P, Lewis SM, Bessler M, Luzzatto L, Dacie JV. Natural history of paroxysmal nocturnal hemoglobinuria. N Engl J Med. 1995;333(19):1253-8.

50. Dacie JL. Paroxysmal nocturnal hemoglobinuria: clinical manifestation, haematology, and nature of the disease. Series Haematol. 1972;3:3-23.
51. Hartmann RC, Jenkins DE Jr, McKee LC, Heyssel RM. Paroxysmal nocturnal hemoglobinuria: clinical and laboratory studies relating to iron metabolism and therapy with androgen and iron. Medicine (Baltimore). 1966;45(5):331-63.

52. Rosse WF. Treatment of paroxysmal nocturnal hemoglobinuria. Blood. 1982;60(1):20-3.

53. Saso R, Marsh J, Cevreska L, Szer J, Gale RP, Rowlings PA, Passweg JR, et al. Bone marrow transplants for paroxysmal nocturnal haemoglobinuria. $\mathrm{Br} \mathrm{J}$ Haematol. 1999;104(2):392-6.

54. De Latour RP, Schrezenmeier H, Mary JY, Baugalupo A, De Souza C, Willemze R, et al. Stem Cell Transplantation for Paroxysmal Nocturnal Hemoglobinuria: An on Going Joint Study of the AAWP EBMT Group and the French Society of Hematology. ASH Annual Meeting Abstracts. Blood. 2008;112(11):3442.

55. Raiola AM, Van Lint MT, Lamparelli T, Gualandi F, Benvenuto F, Figari O, et al. Bone marrow transplantation for paroxysmal nocturnal hemoglobinuria. Haematologica. 2000;85(1):59-62.

56. Hegenbart U, Niederwieser D, Forman S, Holler E, Leiblein S, Johnston L, et al. Hematopoietic cell transplantation from related and unrelated donors after minimal conditioning as a curative treatment modality for severe paroxysmal nocturnal hemoglobinuria. Biol Blood Marrow Transplant. 2003:9(11):689-97.

57. Woodard P, Wang W, Pitts N, Benaim E, Horwitz E, Cunningham J, et al. Successful unrelated donor bone marrow transplantation for paroxysmal nocturnal hemoglobinuria. Bone Marrow Transplant. 2001;27(6):589-92.

58. Endo M, Beatty PG, Vreeke TM, Wittwer CT, Singh SP, Parker CJ. Syngeneic bone marrow transplantation without conditioning in a patient with paroxysmal nocturnal hemoglobinuria: in vivo evidence that the mutant stem cells have a survival advantage. Blood. 1996;88(2):742-50.

59. Kaplan M. Eculizumab(Alexion). CurrOpin InvestigDrugs. 2002;3(7):1017-23.

60. Hillmen P, Hall C, Marsh JC, Elebute M, Bombara MP, Petro BE, et al., Effect of eculizumab on hemolysis and transfusion requirements in patients with paroxysmal nocturnal hemoglobinuria. N Engl J Med. 2004;350(6):552-9.

61. Rother RP, Rollins SA, Mojcik CF, Brodsky RA, Bell L. Discovery and development of the complement inhibitor eculizumab for the treatment of paroxysmal nocturnal hemoglobinuria. Nat Biotechnol. 2007;25(11):1256-64.

Artigo recebido: 30/7/09 Aceito para publicação: 12/11/09 